\title{
Representações sociais sobre a permanência na docência: o que dizem docentes do ensino fundamental?
}

\author{
Ivany Pinto Nascimento ${ }^{1}$ \\ Sônia Eli Cabral Rodrigues ${ }^{1}$
}

\section{Resumo}

Este estudo objetivou analisar as representações sociais de professores do ensino fundamental de escolas públicas sobre a sua permanência na docência na perspectiva das objetivações e ancoragens que organizam essas representações. A metodologia seguida consistiu na pesquisa de caráter descritivo e analítico com referência na Teoria das Representações Sociais. A amostra envolveu 25 professores dos sexos feminino e masculino que trabalham no ensino fundamental. 0 instrumento utilizado para a coleta de informações seguiu a técnica Q que consistiu na ordenação de setenta itens préelaborados sobre a temática em estudo para serem organizados por ordem de importância de acordo com cada informante. A análise das informações dos professores após registro seguiu os procedimentos da referida técnica, baseado no desvio padrão. Os resultados deste estudo destacam que as representações sociais de professores sobre a permanência na docência se organizam da seguinte forma: os docentes do grupo 1 selecionaram frases com sentidos desmotivadores para a permanência na profissão docente. Enquanto que os motivos que os docentes do grupo 2 elegem frases que expressam elementos motivadores para a permanência na docência. Conclui-se que existem polaridades entre as objetivações e as ancoragens nas representações sociais desses professores. As imagens tecidas sobre a profıssão de professor editam uma profissão prazerosa, enquanto que os sentidos atribuídos são desprazerosos e desmotivadores para a permanência na profissão.

\section{Palavras-chave}

Representações sociais de professores - Permanecer - Docência.

1- Universidade Federal do Pará, Belém, Brasil.

Contatos: ivany.pinto@gmail.com; soniaely@ufpa.br 


\section{Socialrepresentationsonthepermanenceinteaching: what do elementary/middle school teachers say?}

\section{Abstract}

The purpose of this study was to analyze the social representations of public elementary/ middle school teachers about their permanence in the profession in the perspective of the objectifications and anchorages that organize these representations. The methodology adopted consisted of descriptive and analytical research whose reference was the Theory of Social Representations. The sample involved 25 female and male teachers from elementary/middle school. The instrument used to collect data followed the $Q$ technique consisting of ordering 70 pre-elaborated items on the subject under study that would be sorted out in order of importance according to each informant. The analysis of teachers' information after recorded followed the procedures of the mentioned technique, based on standard deviation. The results of this study point out that the social representations of teachers about the permanence in teaching are organized as follows: the teachers of group 1 selected phrases with de-motivating meanings for the permanence in the profession. However, teachers of group 2 chose phrases that express motivating elements to remain in teaching. We conclude that there are polarities between the objections and the anchorages in the social representations of these teachers. The images they build about the teaching profession display a pleasant profession, while the meanings assigned to it are unpleasant and de-motivating to go on as a teacher.

\section{Keywords}

Social representations - Teachers - Permanence - Teaching.

\section{Introdução}

Neste artigo, intencionamos discutir os resultados do estudo realizado com o financiamento do CNPq e apoio da Cátedra Unesco de Profissionalização Docente de 2016.

0 estudo focalizou a investigação da permanência na docência de professores do ensino fundamental de escolas públicas, à luz da Teoria das Representações Sociais (TRS) de Serge Moscovici, de modo a verificar as objetivações e as ancoragens que organizam as representações que, por sua, vez orientam pensamentos, sentimentos e ações dos professores para com a sua profissão. Tal estudo se justifica pela importância de entender as imagens e os sentidos que se organizam em torno da permanência na docência, em tempos em que essa profissão entra em questionamento, sobretudo por aqueles que elegeram a docência.

A profissão docente, assim como as demais profissões, se insere em uma sociedade que passa por inúmeras mudanças, onde novas informações e conhecimentos se produzem. Em função disso, as novas demandas se transformam em exigências junto 
aos profissionais para que estes se especializem no sentido de responderem às indagações oriundas das mudanças em nossa sociedade com o seu conhecimento aliado ao exercício de sua profissão.

Assim, esse contexto de transformações que certamente atinge a docência provoca em nós, pesquisadores do campo da educação, a necessidade de analisar questões relacionadas a essa profissão, pois se desejamos trazer para o debate científico a docência na contemporaneidade é importante que se pesquise junto aos docentes do ensino fundamental de escolas públicas as razões pelas quais esses profissionais se mantêm na docência, o que lhes dá satisfação e o que os desafia no exercício da profissão?

\section{Referencial teórico-metodológico}

0 referencial teórico da presente pesquisa consistiu de uma revisão integrativa da literatura sobre as temáticas representações sociais e docência, a partir das bases de dados do banco de teses da Coordenação de Aperfeiçoamento de Pessoal de Nível Superior (Capes). Ressaltamos que o apresentado a seguir é somente uma síntese dessa revisão.

A revisão nos levou a constatar que, embora haja um crescimento de estudos sobre a temática mencionada, ainda é ínfimo o número de trabalhos que abordam as motivações de permanência ou desistência da docência. Foram encontrados trabalhos produzidos entre 2006 e 2012. Quanto ao ano de 2013, não encontramos nenhum estudo a retratar o tema em questão.

Dessa maneira, constatamos que diversos fatores levam os professores a abandonar a docência, tais como: a desvalorização da profissão, a visão de que o professor é um mero reprodutor de conhecimento e os baixos salários. Além disso, há também as péssimas condições de trabalho, isto é, a escassez de recursos, as mudanças na relação professoraluno e as crises na identidade do profissional. Verificamos também que esse abandono, essa desistência, não ocorre de forma imediata, mas gradual, e muitas vezes nem chega a ser percebido pelo próprio docente.

Após revisão dos estudos encontrados, identificamos dois grupos distintos de professores. 0 primeiro é constituído pelos que sentem a profissão como vocação. Renovamse, buscam novos conhecimentos, novas técnicas de ensino, buscam aprimorar o modo como exercem sua função. Esse grupo vislumbra a transformação da profissão, com um novo futuro a partir de suas práticas no presente. 0 segundo grupo são os professores que se dizem acomodados com a sua realidade, lecionam apenas por obrigação, não se sentem realizados com a profissão e, aos poucos, acabam por abandoná-la.

Comumente, essas pesquisas apontam que as condições objetivas, entendidas como aspectos externos da profissão (salário, carreira, prescrições legais, condições concretas de trabalho), são colocadas como entraves ou desafios para permanência na docência, sem mencionar as condições subjetivas, como a vivência diária de um profissional no desempenho do trabalho, incluindo as angústias e as alegrias nas relações sociais que estabelecem - especialmente com seus alunos. Entretanto, essas condições que conjugam fatores extrínsecos e intrínsecos têm estreita relação. Se as condições objetivas do trabalho são ruins, são ruins ou negativos os sentimentos de permanência no trabalho docente. 
Logo, supomos que, se as condições de trabalho melhoram e o papel social do professor também, as condições subjetivas ascendem, a satisfação e o prazer retomam seu lugar.

Observamos também que os resultados de pesquisas e artigos sobre as demandas pelas licenciaturas demonstram um decréscimo, o que se reflete no número de formandos, além da mudança de perfil do público que busca a docência. Essas produções discutem a necessidade de fazer com que a carreira docente seja mais atrativa e que estimule perspectivas promissoras no campo de sua atuação (GATTI et al., 2008; GATTI; BARRETTO, 2009).

A preocupação com a valorização do magistério e com a falta de interesse dos jovens por essa profissão é alvo de preocupação da Organização Internacional do Trabalho (OIT), da Organização das Nações Unidas para a Educação, Ciência e Cultura (Unesco) e também das instituições de ensino superior onde as licenciaturas são ofertadas.

As indagações decorrentes dos resultados dessas e de outras investigações, sobretudo aquelas que temos realizado, nos conduziram aos seguintes questionamentos: como fazer para que a formação de professores e o ensino sejam atrativos aos seus pretendentes? Como a formação inicial e continuada de professores deve ser desenvolvida para manter professores qualificados na profissão? E, por fim, o que faz com que docentes permaneçam ou não na docência? Quais os fatores que contribuem para a permanência na docência e como eles se representam?

Para Soratto e Olivier-Heckler (1999), a profissão docente não possui o mesmo valor de outrora. Na contemporaneidade, a docência deixou de ser uma profissão atraente uma vez que ela padece de inúmeras dificuldades, desde a falta de reconhecimento e valorização, baixos salários, condições precárias de trabalho, até falta de recursos, planos de carreira e formação atualizada, dentre outros agravantes. Em decorrência desse cenário desalentador, a escola se constitui como uma das instituições em que os atributos negativos se sobrepõem muito mais aos positivos e motivadores do trabalho docente.

Essa é uma questão importante na medida em que o desenvolvimento social e econômico de uma nação depende da qualidade da escolarização básica, mais ainda do impulso e do crescimento da sociedade do conhecimento. Para tanto, é imprescindível a existência de professores nas escolas em sua atividade de ensino e de formação das crianças, dos jovens e dos adultos.

Os avanços e transformações na sociedade atual, sem dúvida, nos encaminham para processos de aprendizagens nos quais a lógica que consolida a atividade e a tomada de decisões do sujeito lhe exige formas aprimoradas de lidar com o inusitado e com as adversidades. Na mesma medida, para completar o complexo dessas exigências sobre o sujeito contemporâneo, é imprescindivel que ele possua princípios que são básicos para processos de construção de conhecimentos, como: atenção, percepção, memória, persistência, emoção e afeto, conjugadas com os processos cognitivos acelerados.

Desse modo, a formação aliada ao trabalho docente é imprescindivel e, por isso, deve ser contínua e está relacionada à prática de sua profissão. Nóvoa (2003, p. 23) reitera esses aspectos ao registrar que "0 aprender contínuo é essencial e se concentra em dois pilares: a própria pessoa, como agente, e a escola como lugar de crescimento profissional permanente". Assim, perguntamos: será que a estrutura educacional dos dias atuais propicia um crescimento permanente de seus docentes condizente com as necessidades 
formativas da profissão? Esta indagação suscita em nós muito mais uma provocação do que uma tentativa de fornecer uma resposta.

0 que constatamos na contemporaneidade é o papel do docente e de seu trabalho no processo ensino-aprendizado serem questionados e "postos em xeque" não somente pelo contexto social, em função das transformações acentuadas, mas também pelos índices de reprovação, desinteresse e evasão escolar que continuam a ter altos percentuais e caracterizam a limitação do aproveitamento escolar no Brasil.

Vale acrescentar que existem variáveis de outras ordens: emocional, social, cultural, dentre outras, que interferem no trabalho do professor e que contribuem, sem dúvida, para a caracterização dos fatores que mantém níveis de motivação que refletem no seu trabalho, no processo ensino-aprendizagem e aproveitamento escolar do aluno. Ademais, não se deve perder de vista que esses fatores possuem suas dinâmicas articuladas às idiossincrasias tanto do professor quanto do aluno e de outras dimensões partícipes das suas vidas.

Contudo, a cobrança maior, por vezes, é depositada no trabalho do docente sem atentarmos para a subjetividade que permeia o tipo de permanência em uma carreira como a de professor. Nesse sentido, é importante que se escute o docente que trabalha nas inúmeras modalidades de ensino, os consensos que partilha com seus pares sobre os fatores que mantêm a sua permanência na docência, bem como as implicações no seu trabalho e nos desafios que enfrentam na contemporaneidade.

A compreensão sobre a constituição e a representação dos fatores que incidem sobre a atratividade, a motivação e a permanência nas carreiras profissionais, no caso a docente, necessita considerar as transformações que vêm ocorrendo no mundo do trabalho e nas profissões, envolvendo aspectos de natureza objetiva e subjetiva.

Do ponto de vista objetivo, temos as condições históricas, sociais e materiais determinadas. Os empregos estáveis e remunerados, por exemplo, estão sendo substituídos por formas mais flexíveis de contratos de trabalho (LEVENFUS; NUNES, 2002).

Desde a década de 1980, a sociedade passa por transformações que modificam as formas e as relações de trabalho nos diversos âmbitos profissionais. Isso significa que estamos inseridos em um contexto histórico complexo, cujo cenário de relações sociais e de trabalho refletem essa complexidade, ao introduzir uma nova compreensão de carreira e de desenvolvimento profissional.

Vale lembrar que a palavra carreira tem origem no latim medieval, via a palavra carraria, que significava "correria, corrida". A partir do sentido simbólico atribuído a "correria ou corrida” é que, no século XIX, essa palavra passa a ser empregada à profissão em sua forma atual, ou seja, como percurso de vida profissional, como etapas de uma profissão que apresenta progressão relativa ao nível de formação e de amadurecimento.

Cumpre destacar que a palavra estrada, utilizada para qualifıcar uma profissão, tem o sentido de evolução. No entanto, as carreiras profissionais, nas últimas décadas, em decorrência das mudanças sociais, caracterizam-se pela instabilidade, descontinuidade e horizontalidade.

A noção de trabalho, analisada no contexto atual, segundo Dubar (2006), é a de que, independentemente de sua natureza, ele se tornou um desafio para o sujeito face às exigências cada vez maiores, além de se caracterizar pela incerteza e pela grande implicação social. 
Dessa maneira, os processos de escolha profissional bem como a inserção no mundo do trabalho se encontram inter-relacionados. Isso indica que a escolha profissional não está vinculada somente às características pessoais do sujeito, mas principalmente ao contexto histórico e ao ambiente sociocultural em que ele vive. Implica dizer que a subjetividade e a objetividade do sujeito são construídas, ao mesmo tempo em que ele constrói a realidade sobre as coisas, sobre o mundo e as suas relações. Dai que a escolha profissional e a sua permanência nela carrega um sentido interno para cada sujeito, referente à sua história de vida, mas também possui uma referência externa e coletiva, marcada pelo contexto histórico e social em que o sujeito se encontra inserido e interage com os outros.

As representações sociais das profissões e a permanência nelas, associadas ao status e ao salário, são fatores que certamente influenciam a atratividade para a escolha entre as diferentes áreas de trabalho. Lisboa (2002, p. 30), explica que a escolha do indivíduo é "limitada por objetivos que vão desde as expectativas familiares até subjetivas-objetivas e históricas e sociais".

0 aspecto salarial, embora seja fator forte na determinação da escolha, não é o foco de todas as questões, na medida em que não esgota a atratividade, a motivação e outros fatores que determinam a permanência do sujeito numa profissão (LISBOA, 2002).

Arroyo (2000) considera que um dos problemas enfrentados pelo professor, na contemporaneidade, é a sua descaracterização e desprofissionalização. 0 autor destaca que é importante que haja a ressignificação do lugar, da função do professor e de sua identidade que, segundo ele, "tende a ser afırmada frente à nova descaracterização da escola e da ação educativa” (ARROYO, 2000, p. 22). Esses e outros aspectos corroboram a crise de identidade profissional.

Em sintese, outros elementos, tanto de ordem individual quanto contextual, que compõem a motivação, a emoção, os interesses e as expectativas do sujeito passam a interferir nas suas escolhas, na permanência na profissão e na atividade que o sujeito desenvolve.

A crise de identidade e a crise da profissão docente possuem uma dinâmica interrelacionada, uma vez que as fronteiras que as caracterizam são quase imperceptíveis. Um professor com a autoestima abalada é um profissional fragilizado e vice-versa. Ambos, o professor e a sua profissão, produzem sentidos que se complementam (NASCIMENTO, 2011).

Assim, o projeto profissional é decorrente de fatores extrínsecos e intrínsecos, que se combinam e interagem de diferentes formas, em função dos grupos sociais.

Desse modo, é importante que as discussões sobre a atratividade da carreira docente considerem as fortes contradições levantadas nas pesquisas sobre o "estar professor" (PLACCO; SOUZA, 2012; BARAÚNA et al., 2012). Elas oscilam entre satisfações e frustrações, entre a opção e a necessidade. Aqueles que nela se encontram justificam a sua opção ou pelo aspecto pessoal (amor por esse trabalho, pelas crianças, horário conveniente) ou social (contribuir para o avanço social das comunidades), dentre outras. No entanto, as pesquisas comprovam que, atualmente, a procura pela profissão de professor continua decrescente.

A literatura disponível na área da formação de professores aborda questões que, direta ou indiretamente, se relacionam com a discussão sobre a motivação pela carreira docente e sua permanência nela, como exemplo: a massificação do ensino, a 
feminização do magistério, as transformações sociais, as condições de trabalho, o baixo salário, a formação docente, as políticas de formação, a precarização e a flexibilização do trabalho docente, a violência nas escolas e a emergência de outros tipos de trabalho com horários parciais.

0 trabalho do professor se encontra mais complexo e exige mais responsabilidade. As demandas contemporâneas estabelecem uma nova dinâmica no cotidiano das instituições de ensino, que se reflete diretamente sobre o trabalho dos professores e a sua profissionalidade. Autores como Fanfani (2007), Dussel (2006) e Tedesco (2006) discutem como as mudanças em diversos setores da sociedade contribuem significativamente para a crise de identidade dos trabalhadores da educação e a consequente atratividade e permanência na profissão.

São inúmeros os desafios e atribuições que passam a fazer parte da prática docente. A introdução das tecnologias de ensino no trabalho docente é um dos desafios. Elas produzem mudanças na relação com o conhecimento, o que gera a sensação de obsolescência para muitos profissionais da educação que não as utilizam.

Nesse âmbito de mudanças na relação com e no trabalho, pressupomos que os docentes constituem representações sobre a sua profissão. Assim, neste estudo, a proposta foi estudar as formas como os docentes representam a sua permanência no trabalho docente; como elaboram, transformam e interpretam os fatores que os vinculam ao trabalho de docência no ensino fundamental de escolas públicas.

Assim, com base na Teoria das Representações Sociais (TRS), desenvolvida pelo romeno Serge Moscovici, concebemos as representações sociais como produto das interações entre os indivíduos, que trazem, em sua essência, a maneira pela qual o sujeito ou um determinado grupo constrói significados e conceitos em relação a determinado objeto, levando em consideração as realidades nas quais esses indivíduos ou grupos estejam inseridos, suas ocupações e interesses e objetivos que permeiam as suas ações.

Esses fatores são significativos para que se elabore determinada representação ou para que dela se compartilhe. Elas estão diretamente relacionadas às trocas simbólicas, permanentemente desenvolvidas nos ambientes sociais, por meio das relações interpessoais que se estabelecem entre os indivíduos (MOSCOVICI, 2010).

Moscovici (1978, p. 65) afırma que a representação possui processos envolvidos na atividade representativa. Eles são a objetivação e a ancoragem que possuem a função de organização e representação da realidade. As duas faces articuladas desse processo são: a figurativa e a simbólica que correspondem, respectivamente, a objetivação e a ancoragem. Dessa maneira, representação = figura, significação = sentido na composição das representações sociais, ou seja, a toda figura um sentido e vice-versa.

Nessa lógica, consideramos que a permanência na profissão docente é filtrada e representada em consenso com o seu grupo de pertença. Vale notar que a partilha de ideias, pensamentos, sentimentos e ações feita por esse grupo prevalece para dar sentido e orientar as suas práticas.

Jodelet (2001), psicóloga social francesa e principal colaboradora de Moscovici, destaca a abordagem processual e indica que os saberes tácitos, cujos conteúdos manifestam a operação de processos generativos e funcionais, possuem uma marca social. Essa marca 
dos conteúdos ou dos processos se refere às condições e aos contextos nos quais emergem as representações que refletem a interação do sujeito com o mundo e com os outros.

Os estudos da área de educação em interlocução com o campo das representações sociais permitem a compreensão de como são percebidas pelos sujeitos que atuam no cenário educacional as questões relativas aos fenômenos educacionais e à profissão docente, bem como seus mecanismos, negociações simbólicas, orientadores, balizadores de ações, ou seja, as imagens e os respectivos sentidos que fundamentam as objetivações e as ancoragens que compõem as representações sociais de um grupo sobre um acontecimento ou um objeto social.

Nessa incursão, partimos do pressuposto de que é imprescindível escutar os professores sobre a sua profissão, pois são eles que fazem a prática e a ressignificam, modificando ou reafirmando o modo de sua permanência como docente.

A amostra deste estudo envolveu 25 professores do ensino fundamental, distribuídos entre o sexo feminino e o masculino, que lecionam do $6^{\circ}$ ao $9^{\circ}$ ano do ensino fundamental II de instituições públicas da cidade de Belém e têm de cinco a dez anos de tempo de exercício da profissão. Cumpre destacar que esses professores se encontram lotados em diferentes escolas de ensino fundamental para complementação de carga horária. Essas escolas são classificadas pela secretaria de educação como escolas de médio porte, na medida em que possuem o ensino fundamental desde a $1^{\text {a }}$ série. A escola onde contatamos os professores participantes desta pesquisa fica situada em um bairro da periferia de Belém-PA.

0 instrumento utilizado para a coleta de informações seguiu a técnica Q, e consistiu na ordenação de setenta itens pré-elaborados em forma de frases sobre a temática em estudo para serem organizados por ordem de importância de acordo com cada informante. Essa técnica verifica a frequência com que um determinado acontecimento é observado em uma amostra de dados coletados (GATTI, 1972), neste caso, a dos docentes do ensino fundamental, e se ele se desvia significativamente ou não da frequência esperada, ou seja, da desmotivação pela carreira docente, encontrada nas produções que tratam do tema.

A análise das informações dos professores, após o seu registro na planilha desenvolvida a partir do software Excel, seguiu os procedimentos e tratamento da referida técnica, com base na lógica estatística do desvio padrão. Usamos a análise de conteúdo para a leitura dos agrupamentos gerados por esse tratamento. Acrescentamos que utilizar a teoria das representações como suporte teórico, conforme mencionado, para conhecer as representações sociais que os docentes do ensino fundamental de escolas públicas atribuem à sua permanência na docência implicou em identificar as objetivações (imagens) e as ancoragens (sentidos) que organizam essas representações.

Para tanto, após os agrupamentos das informações dos docentes, operacionalizados pela análise de conteúdo de Bardin (1976), foi possível efetivar o levantamento dos significados que estruturam as representações sociais desses docentes informantes.

\section{Análise e discussão}

Neste estudo, a proposta foi estudar as formas como os docentes representam a sua permanência no trabalho docente, ou seja, como elaboram, transformam e interpretam os fatores que os vinculam ao trabalho da docência no ensino fundamental de escolas públicas. 
A análise apresentada versará sobre a média aritmética, onde se concentram as maiores frequências das frases selecionadas pelos sujeitos e, de acordo com a análise referenciada pela técnica Q, os resultados indicaram dois grupos de frequências, nomeados de Grupo 1 e Grupo 2. Vale acrescentar que a eleição das frases desses dois grupos nos fornece subsídios para a compreensão dos fatores que concorrem para permanência dos professores na docência. Por isso, abordamos aquelas frases de maiores frequências em ambos os grupos. No geral, essas frases, em conjunto, se assemelham em suas imagens e sentidos que pautam as representações atreladas aos significados, estas constituídas nas partilhas, vivenciadas no trabalho dos docentes no ensino fundamental em escolas públicas.

Os docentes do Grupo 1, conforme as concentrações de frequência, selecionaram frases com sentidos mais desmotivadores do que motivadores para a permanência na profissão docente. Assim, a respeito do que pensam os professores em relação a si mesmos, relacionamos as seguintes frases:

- Eu não me sinto preparada para dar aula.

- Eu tenho vergonha da minha profissão.

- Eu queria ter uma profissão diferente da que tenho.

- Eu engulo sapo a cada dia.

- Todo dia tenho dor de cabeça quando chego à escola.

Essas frases nos revelam uma imagem de pouca valorização da profissão em função dos processos formativos e do trabalho que desenvolvem.

Segundo Gatti (2013), a representação de não valorização da docência na educação básica persiste, uma vez que a constituição sócio-histórica e política de elementos para a superação e reconstrução dessas representações sociais está longe de ser alcançada.

Essas frases, escolhidas pelos docentes, também envolvem aspectos cognitivos e emocionais do processo de formação e do próprio trabalho docente. A prática profissional cada vez mais exige novos saberes e conhecimentos que, na maioria das vezes, não são vistos no processo de formação. Por outro lado, a emergência de novos assuntos interpostos nas relações com os alunos em sala de aula a todo momento coloca os docentes à prova, visto que eles expressam que vivenciam um misto de emoções, muitas vezes contraditórias, se sentem simultaneamente aborrecidos, entusiasmados, alegres e tristes (CASASSUS, 2009).

De outro modo, esses professores atribuem outros fatores à desmotivação pela profissão docente, na medida em que elegem as seguintes frases:

- 0 Estado não reconhece o nosso trabalho.

- Os jornais não valorizam o professor.

- A escola não oferece condições para ensinar.

- Os alunos são desrespeitosos.

- Levanto muito cedo para ir à escola; a diretora não é compreensiva.

- A culpa de o ensino ser ruim é do Estado.

- É uma profissão bastante defasada.

- A formação que recebemos é inadequada.

- Essa profissão passou a ser desvalorizada.

- Os pais põem a culpa no professor pelo insucesso.

- A escola quer que a gente seja babá de aluno.

- 0 Estado paga muito mal. 
- A sala de aula é muito quente.

- Os pais não deixam a gente fazer o nosso trabalho.

- Esta profissão me trouxe problemas de saúde.

As frases eleitas pelos professores permitem identificar a coexistência de diferentes questões, que envolvem a partilha de representações sociais sobre a desvalorização da profissão docente, numa relação direta com a precarização de seu trabalho. Além das péssimas condições estruturais das escolas, eles se ressentem do apoio dos pais, das equipes pedagógicas e escolares. São frases que apresentam contextos concretos da educação brasileira que incidem na relação dialógica desses professores e que contribuem para a imagem de precarização do trabalho docente (GATTI, 2013).

Quanto às frases com maior frequência sobre o sentido de ser professor, as escolhas indicam as seguintes frases:

- É ter sabedoria.

- É dar sem receber.

- É um dom de Deus.

- É a melhor das profissões.

- É uma profissão que dá prestígio.

- Exige muita paciência.

- É padecer no paraíso.

Nesse agrupamento de frases, o ser professor está ligado a representações de significados altruístas, de realização pessoal e se articula fortemente à imagem de si e à experiência cotidiana, a saber: o dom e a vocação, o amor pelas crianças, pelo outro, pela profissão, pelo saber e a necessidade de conquistar logo certa autonomia financeira (VALLE, 2006).

Desse modo, ocorre a opção pelo magistério, visto que essas imagens residem sobre algumas lógicas que estão relacionadas com as representações que os sujeitos têm de si mesmo, e dos significados atribuídos à inserção no mundo do trabalho e, em particular, ao exercício da docência, como explica Valle (2006).

Quanto às frases eleitas pelo Grupo 2, observamos que os motivos que os docentes elegem para demonstrar a sua permanecia na profissão objetivam imagens como:

- É uma profissão que exige heroísmo.

- É a melhor das profissões.

As frases mais frequentes eleitas pelos participantes da pesquisa sobre a permanência na docência ancoram significados como:

- A falta de opção para eleger outra profissão.

- A garantia da sobrevivência da família por ser o trabalho do professor mais seguro do que o de outras profissões.

- A atribuição de ser a profissão de professor um vício, como se não tivesse saída.

As frases presentes indicam motivos ambivalentes para a permanência na docência. Comparecem significados e sentidos que corroboram estudos realizados anteriormente (NASCIMENTO, 2011), nos quais constatamos que, infelizmente, um número significativo de professores do $1^{\circ}$ e do $2^{\circ}$ grau abraçou a profissão porque não havia alternativa na região onde moravam, ou entraram no curso de magistério em consequência de não terem obtido nota para o curso pretendido. 
Dessa maneira, uns descobrem que possuem motivação para exercer a profissão de professor após a entrada na faculdade, quando iniciam o estágio docente ou ainda quando começam a trabalhar. Outros saem da faculdade formados, sabedores de que não possuem motivação e nem habilidades desenvolvidas ou, ainda, se encontram em dúvidas sobre exercer a carreira de magistério, todavia insistem em inserirem-se nela.

Acreditamos que se os cursos de licenciatura insistissem em debates sobre a formação de professores e seus respectivos currículos, articulados com a prática pedagógica e necessários para as vivências do aluno com a profissão, contribuiriam em grande medida para a compreensão cada vez mais abrangente e significativa da realidade (MIZUKAMI, 1986). Existe diferença entre o aluno somente escutar e discutir com base em idealizações e o aluno escutar e discutir o que praticou e vivenciou.

Os conflitos se iniciam possivelmente quando as demandas sobre o trabalho do professor vão além de sua formação, visto que exigem decisão, criação, senso crítico e outros aspectos, como: gostar e saber o que faz, para que o professor possa reivindicá-las.

Como explica Fanfani (2007), a sociedade exige da escola muito mais do que ela pode ofertar. Vale notar que existe uma lacuna entre a imagem ideal do docente e a realidade relacional e temporal da sua prática e de seu trabalho. No cotidiano da escola, o professor, para desenvolver a atividade de ensinar, precisa saber lidar com problemas de indisciplina e violência, falta de interesse de alunos, necessidade de trabalhar com um número elevado de alunos e desenvolver sua tarefa educativa na e para a diversidade.

0 que observamos na frequência de frases eleitas pelos 25 professores é que existe um desprazer crescente em relação à profissão de professor. Esse desprazer se ancora em sentidos que se transformam em queixas sobre a infraestrutura e a localização da escola, alunos que não desejam aprender, pais de alunos que não ajudam na aprendizagem de seus filhos e nem os educam, e, ainda, o Estado que, na visão desses professores, deveria valorizar a profissão com remuneração adequada.

Essas frases partilhadas remetem ao descontentamento pela desvalorização da profissão docente que, para esses professores, poderia ser mais valorizada por meio de melhores salários.

Nesse sentido, essas representações denunciam o descontentamento com a profissão docente. Placco e Souza (2012, p. 130), apoiadas em Moscovici, afirmam: "o indivíduo se projeta naquilo que representa, constrói a si a partir de suas representações dos objetos, do mesmo modo que forma representações dos objetos a partir daquilo que considera como pertencente à sua identidade”.

Desse modo, as atribuições dos sentidos são apresentadas em sua relação tanto na perspectiva individual quanto social dos sujeitos, portanto, atravessa a dimensão afetiva, representacional e, por conseguinte, o mundo do trabalho e se manifesta por meio das práticas orientadas pelos conteúdos figurativos e sentidos constitutivos das representações sociais.

Esse baixo valor social e governamental da profissão docente configura-se, para esses professores, em imagens e sentidos de desvalorização da docência, pela precarização do trabalho docente, nas contradições entre a formação e a realidade educacional. Isso tudo reverbera negativamente, num processo de desmotivação para a docência. Nesse 
contexto, inferimos que a permanência na profissão docente esteja ancorada na antiga representação desta como missão, vocação ou dom.

A forma como a escola e o ensino se encontram atualmente, cada vez mais determinados por uma política alheia tanto às necessidades do professor quanto às demandas do alunado, faz com que as atividades pedagógicas sejam cumpridas pelos professores muito mais como técnica do que como atividade de planejamento, fruto de discussão, estudos e planejamento entre os professores.

Com efeito, o professor não desenvolve a sua criatividade e não partilha ideias com os seus colegas de trabalho com vistas a se sentir parte responsável do que faz e ensina na sua profissão. A justificativa da escola recai nas determinações da Secretaria de Educação ou outro órgão afim, que exerce de forma hegemônica a coordenação na rede escolar.

A eleição da profissão de professor aparece para esses professores vinculada a motivações objetivas, pessoais e familiares, como nas seguintes frases de maiores frequências:

- Eu não queria ser professora, mas minha família desejava que eu fosse.

- Não escolhi, mas estou contente.

- É a profissão que combina com a função de ser mãe e dona de casa.

Observamos nessas frases que, segundo Valle (2006), o gênero sexual funciona também como uma das variáveis na motivação e escolha pela docência em nossa sociedade, na medida em que a maioria dos licenciandos e docentes nas redes de ensino são do sexo feminino.

A feminização do magistério não está vinculada somente à presença massiva de mulheres na profissão docente, mas também à associação das práticas, atividades e significados dessa profissão ao universo feminino, independentemente de quem os corporifica, conforme nos ilustra Carvalho (1999).

Notamos, também, que tomar para si a responsabilidade de ser professor parece frágil. A escolha da profissão segundo habilidades pessoais, formação de nível superior realizada, ou ainda outros fatores que apontem para a escolha profissional - direcionados a aspectos importantes que devem ser desenvolvidos para o exercício da carreira docente - parece distante.

A insatisfação geradora do desprazer em relação o trabalho manifestado por esses professores do ensino fundamental encontra suas raízes nas condições de trabalho, nos baixos salários, na inadequação dos critérios de ascensão na carreira profissional, na falta de qualificação para acompanhar as mudanças e as demandas dos alunos. Esses fatores de insatisfação fazem com que os professores exerçam a sua profissão cada vez mais desmotivados, o que leva à acomodação e à resistência para renovar-se e para capacitarse melhor. 0 trabalho docente, desse modo, se transforma em uma rotina sem nenhum sentido, acréscimo ou reorganização (FRANCHI, 1995).

Perguntamos: onde estaria a fonte de satisfação do professor na contemporaneidade? 0 que motiva o professor para o trabalho? As pesquisas afirmam que a maior fonte de satisfação do professor ainda é ensinar (MOREIRA, 1996). Por outro lado, segundo Franchi (1995), a permanente desvalorização da profissão docente e suas atuais condições fazem com que os professores sintam que o prazer de ensinar seja cada vez menor. 
Possivelmente, uma formação de qualidade na preparação do professor durante o curso pode fazer a diferença, no sentido de aumentar a clareza e definição na escolha da profissão, bem como assegurar níveis de prazer e luta por eles no desempenho da profissão. Sabemos que a queixa não motiva e nem dissipa os problemas inerentes da profissão. A motivação e o envolvimento com o exercício da profissão mobilizam diálogos e alternativas para mudanças. Acrescentamos que não estamos desconsiderando os fatores que desmotivam a permanência na docência, e sim fazendo algumas provocações que julgamos pertinentes e que valem também para nós, professores do ensino superior.

\section{Considerações finais}

Como foi possível perceber, as representações sociais fazem parte da vida diária das pessoas e da sociedade. Elas carregam em si a força do pensamento dos indivíduos que, inseridos no contexto social, vivenciam os sabores e dissabores de um cotidiano, cuja característica principal consiste na rítmica produção de sentidos e possibilita alternadamente a vivência, individual e coletiva, da alegria e da dor, do prazer e do sofrimento, do contentamento e da frustração.

Neste estudo, as representações sociais sobre a permanência ou não na docência ensejam imagens ambivalentes, positivas e negativas que, por sua vez, influenciam os motivos e a desmotivação para permanecer na docência.

Quanto às imagens positivas persiste a vinculação da profissão de professor como um sacerdócio, dom, vocação. E isso parece sustentar a missão de ser professor mesmo nas condições mais precárias da educação. As imagens negativas dão conta da desvalorização do trabalho docente em função da carreira pouco promissora, das difíceis condições concretas das escolas públicas e, ainda, da falta de motivação dos alunos pela escola e pelo ensino.

Essa atribuição de significados e sua compreensão são definidoras das imagens que repercutem no seu discurso sobre a desmotivação para permanecer na docência. Isso nos possibilita a compreensão das objetivações das representações dos professores.

As representações sociais de professores do ensino fundamental sobre a permanência na docência se organizam entre objetivações que se articulam a um forte desprazer vivido na profissão por esses docentes. Constatamos que as representações sobre a permanência estão ancoradas nas representações sociais que vinculam a profissão a missão e dom para docência. Implica dizer que as imagens tecidas sobre a profissão de professor revelam uma profissão desafiadora e altruísta, mas, ao mesmo tempo, vivida de modo desmotivador, dadas as condições de precarização da docência no contexto da educação brasileira.

Para além das questões reais, geradoras de desprazer em relação à profissão, existem outras que merecem reflexão e reação nos cursos de licenciatura e pelos professores em exercício. Outro modo de organização dos cursos formadores de professores e da escola pública em torno da formação para a docência poderá ser um caminho de ressignificação do trabalho docente. Fazê-lo significa fundamentar os processos de formação com políticas e conhecimentos articulados à teoria e à prática. Atualmente, a formação de professores e a capacitação em serviço caminham na contramão da realidade do trabalho do professor, ou 
seja, essa formação se distancia da concepção do professor como sujeito crítico-reflexivo, que necessita da "reflexão na ação, da reflexão sobre a ação e da reflexão sobre a reflexão na ação” (PIMENTA; GHEDIN, 2002, p. 29).

\section{Referências}

ARROYO, Miguel. Fracasso-sucesso: o peso da cultura escolar e do ordenamento da educação básica. In: ABRAMOWICZ, Anete; MOLL, Jaqueline (Org.). Para além do fracasso escolar. Campinas: Papirus, 2000. p.11-26.

BARAÚNA, Rita de Cássia de Alcântara et al. Identidade profissional e representações sociais do trabalho docente: o lugar da experiência na formação da pedagoga. In: PLACCO, Vera Maria Nigro de Souza; VILLAS BÔAS, Lúcia Pintor Santiso; SOUZA, Clarilza Prado de (Org.). Representações sociais: diálogos com a educação. Curitiba: Champagnat: Fundação Carlos Chagas, 2012. p. 35-40.

BARDIN, Laurence. Análise de conteúdo. Lisboa: Edições 70, 1976.

CARVALHO, Marília Pinto de. No coração da sala de aula. São Paulo: Xamã, 1999.

CASASSUS, Jaime. Fundamentos da educação emocional. Brasília, DF: Unesco: Líber, 2009.

DUBAR, Claude. A crise das identidades: a interpretação de uma mutação. Lisboa: Afrontamento, 2006.

DUSSEL, Inés. Impactos de los cambios en el contexto social y organizacional del oficio docente. In: DUSSEL, Inés. El oficio de docente: vocación, trabajo y profesión en el siglo XXI. Buenos Aires: Siglo XXI, 2006. p. 35-40.

FANFANI, Emilio Tenti. Consideraciones sociológicas sobre profesionalización docente. Educação \& Sociedade, Campinas, v. 28, n. 99, p. 335-354, maio/ago. 2007.

FRANCHI, Eglê Pontes (Org.). A causa dos professores. Campinas: Papirus, 1995.

GATTI, Bernadete Angelina. A utilização da técnica Q como instrumento de medida nas ciências humanas. Cadernos de Pesquisa, São Paulo, n. 6, p. 46-51, 1972.

GATTI, Bernadete Angelina. Valorização da docência e avaliação do trabalho docente: o papel da avaliação participativa em contexto institucional. In: GATTI, Bernadete Angelina (Org.). 0 trabalho docente: avaliação, valorização, controvérsias. Campinas: Autores Associados: Fundação Carlos Chagas, 2013. p. 58-59.

GATTI, Bernadete Angelina; BARRETTO, Elba Siqueira de Sá. Professores: aspectos de sua profissionalização, formação e valorização social. Relatório de Pesquisa. Brasília, DF: Unesco, 2009.

GATTI, Bernadete Angelina et al. Formação de professores para o ensino fundamental: instituições formadoras e seus currículos: relatório de pesquisa. São Paulo: Fundação Carlos Chagas; Fundação Vitor Civita, 2008. 2 v. 
JODELET, Denise. Representações sociais: um domínio em expansão. In: JODELET, Denise (Ed.). As representações sociais. Rio de Janeiro: UERJ, 2001. p. 17-44.

LEVENFUS, Rosane Schotgues; NUNES, Maria Lúcia Tiellet. Principais temas abordados por jovens centrados na escolha profissional. In: LEVENFUS, Rosane Schotgue; SOARES, Dulce Helena Penna (Org.). Orientação vocacional ocupacional: novos achados teóricos, técnicos e instrumentais para a clínica, a escola e a empresa. Porto Alegre: Artmed, 2002. p. 44-55.

LISBOA, Mário Dionísio. Orientação profissional e mundo do trabalho: reflexões sobre uma nova proposta frente a um novo cenário. In: LEVENFUS, Rosane Schotgue; SOARES, Dulce Helena Penna (Org.). Orientação vocacional ocupacional: novos achados teóricos, técnicos e instrumentais para a clínica, a escola e a empresa. Porto Alegre: Artmed, 2002. p. 34-36.

MIZUKAMI, Maria da Graça Nicoletti. Ensino: as abordagens do processo. São Paulo: EPU, 1986.

MOREIRA, Herivelto. A investigação da motivação do professor: a dimensão esquecida. Revista Educação e Tecnologia, Curitiba, v.1, n.1, p. 88-96, out.1996.

MOSCOVICI, Serge. A representação social da psicanálise. Rio de Janeiro: Zahar, 1978.

MOSCOVICI, Serge. Representações sociais: investigações em psicologia social. 7. ed. Editado em inglês por Gerard Duveen e traduzido do inglês por Pedrinho A. Guareschi. Petrópolis: Vozes, 2010.

NASCIMENTO, Ivany Pinto do. As representaçãoes sociais dos professores do ensino fundamental enlaçadas ao que relaizam na escola. In: NASCIMENTO, Ivany Pinto do. Relatório final das atividades desenvolvidas entre janeiro de 2011 a novembro de 2011 junto ao Programa de Pós-Graduação em Educação PROPED da Universidade Estadual do Rio de Janeiro. Rio de Janeiro: UERJ, 2011. p. 05-20.

NÓVOA, António (Org.). Cúmplices ou reféns? Nova Escola, São Paulo, n. 162, p. 14-15, abr./ maio 2003.

PIMENTA, Selma Garrido; GHEDIN, Evandro (Org.). Professor reflexivo no Brasil: gênese e crítica de um conceito. São Paulo: Cortez, 2002.

PLACCO, Vera Maria Nigro de Souza; SOUSA, Vera Lúcia Trevisan de. Movimentos identitários de professores e representações do trabalho docente. In: PLACCO, Vera Maria Nigro de Souza; VILLAS BÔAS, Lúcia Pintor Santiso; SOUZA, Clarilza Prado de (Org.). Representações sociais: diálogos com a educação. Curitiba: Champagnat: Fundação Carlos Chagas, 2012. p. 22-23.

SORATTO, Lucia; OLIVIER-HECKLER, Cristianne. Educação: carinho e trabalho. In: CODO, Wanderley (Org.). Escola: uma organização multiprofissional. v. 1. Petrópolis: Vozes, 1999. p. 122-138.

TEDESCO, Juan Carlos. A modo de conclusión: una agenda de política para el sector docente. In: TEDESCO, Juan Carlos. El oficio de docente: vocación, trabajo y profesión en el siglo XXI. Buenos Aires: Siglo XXI, 2006. p. 13-15. 
VALLE, Ione Ribeiro. Carreira do magistério: uma escolha profissional deliberada? Revista Brasileira de Estudos Pedagógicos, Brasília, DF, v. 87, n. 216, p. 178-187, ago. 2006.

Recebido em: 04.07.2016

Aprovado em: 22.11.2016

Ivany Pinto Nascimento é docente associada do Programa de Pós-Graduação em Educação da Universidade Federal do Pará (UFPA), bolsista produtividade- CNPq, coordenadora do Grupo de Estudos e Pesquisas sobre Juventude, Identidade Representações Sociais e Educação (GEPEJURSE).

Sônia Eli Cabral Rodrigues é docente adjunta da Faculdade Educação do Instituto de Ciências da Educação da Universidade Federal do Pará (ICED/UFPA). Vice-coordenadora do Grupo de Pesquisa Juventude, Identidade, Representações Sociais e Educação (GEPEJURSE), cadastrado no CNPq. 